\title{
O PROCESSO FORMATIVO DO SUJEITO: GOVERNAMENTALIDADE E MODOS DE SUBJETIVAÇÃO COMO PROCESSO DE SINGULARIZAÇÃO A PARTIR DO CUIDADO DE SI
}

\author{
THE FORMATIVE PROCESS OF SUBJECT: GOVERNMENTALITY AND SUBJECTIVATION MODES AS SINGULARIZATION \\ PROCESS FROM THE SELF'S CARE
}

\section{EL PROCEDIMIENTO FORMATIVO DEL SUJETO: GOBERNAMENTALIDAD Y MODOS DE SUBJETIVACIÓN COMO PROCEDIMIENTO DE SINGULARIZACIÓN A PARTIR DEL CUIDADO DE SÍ}

\author{
MOTA, Fernanda Antônia Barbosa de ${ }^{1}$
}

\begin{abstract}
RESUMO
O presente estudo visa investigar a relação entre as noções de sujeito, governamentalidade e subjetivação no pensamento foucaultiano. Inicialmente, discorre sobre o modo como o processo formativo do sujeito está atrelado às relações de poder a partir das tecnologias educacionais. Em seguida, mostra como o sujeito pode se constituir, sendo que ao mesmo tempo em que se assujeita, também cria modos de subjetivação a partir de técnicas de si. Posteriormente, trata das noções foucaultiana de práticas de si, que implicam na assunção das noções de cuidado de si e parrhesía . O aporte teórico de nosso estudo baseia-se em autores como: Foucault (2004; 2012; 2013a; 2013b), Deleuze (1992; 2005), Aspis (2011), Pagni (2011; 2012), Kohan (2000; 2008), Muchail $(2004 ; 2011)$, Freitas (2012), dentre outros. Finalmente, o estudo evidencia que através da criação dos modos de subjetivação podemos experimentar outro modo de viver e resistir ao buscar nas técnicas de si essa transformação.
\end{abstract}

Palavras-chave: Educação das Relações Étnico-Raciais. Ensino Fundamental. Experiências Escolares.

\section{ABSTRACT}

The present study aims to investigate the relationship between the notions of subject, governmentality and subjectivation in Foucaultian thought. Initially, it discusses how the subject's formative process is linked to the power relations from the educational technologies. Then, it shows how the subject can be constituted, while at the same time that he dominated also creates modes of subjectivation from techniques of self. Later, it deals with the Foucaultian notions of self practices, which imply the assumption of the notions of self care and parrhesia. The theoretical contribution of our study is based on authors such as: Foucault (2004; 2012; 2013a; 2013b), Deleuze (1992; 2005), Aspis (2011), Pagni (2011; 2012), Kohan (2000; 2008), Muchail (2004; 2011), Freitas (2012) among others. Finally, the study shows that through the creation of modes of subjectivation we can experience another way of living and resisting by seeking in the techniques of this transformation.

Keywords: Governmentalitye; Subjectivation; Self's care.

\section{RESUMEN}

El presente estudio busca investigar la relación entre las nociones de sujeto, gubernamentalidad y subjetivación en el pensamiento foucaultiano. Inicialmente, discurre sobre el modo en que el proceso formativo del sujeto está vinculado a las relaciones de poder a partir de las tecnologías educativas. En seguida, muestra cómo el sujeto puede constituirse, al mismo tiempo que se asocia, también crea modos de subjetivación a partir de técnicas de sí. Posteriormente, trata de las nociones foucaultiana de prácticas de sí, que implican en la asunción de las nociones de cuidado de sí y parrhesía. El aporte teórico de nuestro estudio se basa en autores como: Foucault (2004, 2012, 2013a, 2013b), Deleuze (1992; 2005), Aspis (2011), Pagni (2011; 2012), Kohan (2000; 2008), Muchail $(2004,2011)$, Freitas (2012), entre otros. Finalmente, el estudio evidencia que a través de la creación de los modos de subjetivación podemos experimentar otro modo de vivir y resistir al buscar en las técnicas de sí.

Palabras clave: Gobernabilidad; Subjetivación; Cuidado de sí.

\section{INTRODUÇÃO}

\footnotetext{
1 Universidade Federal do Piauí - UFPI - Teresina - Piauí - Brasil.
} 
O presente artigo tem como objetivo discutir a relação entre as noções de sujeito, governamentalidade, modos de subjetivação e práticas de si no pensamento foucaultiano. $O$ artigo encontra-se dividido em três seções:

$\mathrm{Na}$ primeira, "Governamentalidade: o sujeito fabricado/construído pelas tecnologias educacionais e pelas práticas de si", essa discussão é importante para evidenciar a atualidade de tais noções nas instituições educacionais onde ocorrem assujeitamentos, mas onde também podem ser criados modos de subjetivação que se constituem nas relações de poder entre os movimentos de dominação e resistência. Pois a nossa experiência é a utilização que fazemos do saber para dar sentido a nossa prática. Se nossa experiência está atrelada ao modo de constituição de nossas subjetividades podemos nos constituir como sujeitos conformados ou não, ou seja, ao mesmo tempo em que somos capazes de resistência a essa forma de constituição, também somos capazes de criar brechas para reinvenção, o que significa, simultaneamente se sujeitar a ela e nela se subjetivar. A partir da experimentação de si pode surgir uma nova forma de arte da vida ou novos modos de existência como atitude política e ética.

Na segunda seção, "A constituição de si a partir dos modos de subjetivação", objetiva mostrar como o sujeito pode se constituir, sendo que ao mesmo tempo em que se sujeita ao instituído, também cria modos de subjetivação a partir de técnicas de si, no intuito de querer construir uma prática educativa que não se paute apenas pelo acúmulo de conhecimento, sujeito da razão, mas que crie brechas para novos modos de existência. A partir da teoria foucaultiana procederemos a um recorte do pensamento estoico, no qual o sujeito ético é privilegiado, compreendido como o indivíduo que se constitui a si próprio a partir de sua relação consigo e com os outros num espaço tensionado por forças disciplinares instituídas. No vocabulário deleuziano, as tentativas de fuga do indivíduo ao enquadramento molar são chamadas de produção de novos modos de existência, novas possibilidades de vida ou existência como obra de arte. Na terminologia foucaultiana, o modo como o indivíduo se comporta ou se posiciona em relação a tais forças pode ser chamado de práticas de si, tecnologias de si ou artes da existência. Essa questão está diretamente atrelada ao tema da experimentação de si ou subjetivação. Esse tema será abordado a partir do enfoque dado por Deleuze $(2005,1992)$ e principalmente por Foucault (2004; 2012; 2013a; 2013b), que relacionam a experiência com os modos de subjetivação. A despeito das diferentes denominações, trata-se de referências à noção de modos de subjetivação. No presente artigo, privilegiaremos a perspectiva de Foucault (2004; 2012; 2013a; 2013b) acerca dos modos de subjetivação.

Na terceira seção, "Práticas de si", será conferida especial atenção à noção foucaultiana de práticas de si, que implicam na assunção das noções de cuidado de si e parrhesía como centrais para a retomada da experiência como subjetivação. Foucault (2004) explica que existem três modelos principais no que se refere à questão do cuidado de si: o modelo platônico, o modelo cristão e o modelo helenístico-romano. Após explicitarmos estes modelos, ressaltamos, a parrhesía caracterizada como uma atitude de franqueza de pensamento, de coração e de palavra, o que requer do sujeito uma transformação de si, como um trabalho ético e estético em sua própria existência. 


\section{GOVERNAMENTALIDADE: O SUJEITO FABRICADO/CONSTRUÍDO PELAS TECNOLOGIAS EDUCACIONAIS E PELAS PRÁTICAS DE SI}

$\mathrm{Na}$ busca por uma mudança mais adequada de nossa própria existência e de uma conduta pautada por uma ação cada vez mais capaz de expô-la no mundo, poderíamos fazer da constituição de nossa própria subjetividade objeto de nosso pensar. No entanto, modernamente, as subjetividades e a experiência que impulsionam o pensar foram substituídas por tecnologias de fabricação de subjetividades dóceis, por uma certa seriação que não fugisse dos mecanismos de controle e dominação. Assim, na constituição tradicional das subjetividades, pouco importou as deliberações do sujeito que foram moldadas, enformadas, de modo que ele não tenha se dado conta disso, além de ter suas experiências pautadas na noção de reprodução ao instituído.

Na auto-avaliação acerca da sua trajetória filosófica, Foucault (2013a) evidencia que a temática central de seu trabalho nos últimos vinte anos fora a questão do sujeito: os modos como os seres humanos se transformam em sujeitos. Para ele, o sujeito é constituído mediante um jogo de forças protagonizado pelas imposições exteriores (práticas coercitivas) oriundas das relações de saber e de poder, e pelas relações intersubjetivas (práticas de liberdade) com si mesmo e com os outros. Na sua perspectiva, o principal objetivo contemporâneo não deveria ser a descoberta do que somos, mas a resistência ao que somos em conexão com o compromisso de tentar imaginar e construir o que efetivamente poderíamos vir a ser.

Todavia, diferentemente da concepção defendida por Foucault (2013a), a noção de sujeito que predomina no âmbito educacional ainda permanece atrelada ao legado moderno, que definiu a subjetividade como algo já dado, estável e de caráter universal. Nessa acepção, o sujeito seria passível de ser educado e a educação seria o instrumento certo para moldá-lo a fim de torná-lo o que ele essencialmente é, lapidado pelas tecnologias educacionais. Como o sujeito foi produzido, sua liberdade de pensamento e experiência também foram obstados pela obediência ao instituído, ou seja, pela educação, que seria apenas uma dessas ferramentas atreladas à sistematização científica e técnica. Essa exclusão da experiência equivale a uma tentativa de impedimento da relação consigo mesmo. $\mathrm{Na}$ noção foucaultiana de sujeito não é possível falar de figuras modelares de aluno ou de professor, mas sim de variáveis figuras de alunos e de professores, isto é, sujeitos que estão sempre em construção, em contato, em articulação e interferência mútua e que possam se constituir a partir de sua relação com o mundo, com a vida e consigo mesmo.

$\mathrm{Na}$ noção foucaultiana de subjetivação, o sujeito não é universal, mas uma construção histórica. Diferentemente da concepção moderna na qual a educação é considerada o processo universal mediante o qual o sujeito é fabricado, na concepção foucaultiana a educação não é o único elemento do processo formativo do sujeito, visto que este também se constitui a partir de suas outras relações sociais e de sua relação consigo mesmo a partir das técnicas de si. Todas essas relações 
possibilitam a constituição provisória do sujeito, provisória porque o sujeito não é estático e está em constante transformação.

O problema evidenciado aqui diz respeito ao modo como o processo formativo do sujeito está atrelado às relações de poder, ao modo como o sujeito foi pensado como sujeito da razão. Modo este que exclui do processo formativo do sujeito sua relação com o mundo e consigo mesmo, especificamente, no exercício de poder nas sociedades modernas que consiste na condução de condutas e na ordenação da probabilidade que denominamos de governo. Em outras palavras, governar é "um modo de ação sobre a ação dos outros" e uma tentativa de "estruturar o eventual campo de ação dos outros" (FOUCAULT, 2013a, p. 288-289). Como forças, as relações de poder se afetam mutuamente e se entrecruzam nos diversos espaços constituintes de uma sociedade.

Através dos tempos, as relações de poder foram progressivamente governamentalizadas: "elaboradas, racionalizadas e centralizadas na forma ou sob a caução das instituições do Estado" (FOUCAULT, 2013a, p. 293). Dessa forma, além de os poderes instituídos exercerem um controle sobre a produção das subjetividades na medida em que elege um modelo de sujeito a ser fabricado no espaço escolar, também se previne contra a proliferação de subjetividades. Conforme explica Aspis (2011, p. 172-173), a governamentalidade captura a multiplicidade e a reduz a pares opostos: "As sociedades disciplinares instauram a reprodução; assim roubam a imprevisibilidade, o imponderável, o novo, a vida".

Em outro registro, as relações de poder na filosofia foucaultiana são descritas na sua amplitude como relações moleculares em torno de uma instância molar, "se entendermos por 'governo' o poder de afetar sob todos os aspectos" (DELEUZE, 2005, p. 84). Isso pode ser melhor compreendido se considerarmos que o poder não está localizado em indivíduos ou instituições porque todas as relações humanas são permeadas pelo poder.

Foucault (2013a) adverte que embora o sujeito não esteja totalmente à mercê do poder que se exerce sobre ele, sua liberdade fica restringida à capacidade de resistir a determinadas formas de sujeição. Trata-se de um jogo de forças porque assim como o poder só pode ser exercido contra homens livres, a liberdade é a pré-condição para a existência do poder. As relações de poder são jogos de verdade ou jogos estratégicos entre liberdades nos quais uns tentam sobrepujar os outros através da determinação de suas condutas e os outros podem resistir ou não a esse estado de dominação, recusando que sua conduta seja determinada ou, em contrapartida, também tentando determinar a conduta de seus opositores (FOUCAULT, 2012).

A esse respeito, destacamos que a noção de resistência aqui é pensada como um movimento contrário e permanente no âmbito do exercício do poder, pois como afirma Foucault (2013a, p. 293294): "não há relação de poder sem resistência".

Todavia, o comprometimento de professores e alunos com uma outra perspectiva de existência, que foge do instituído, faz com que mesmo nesses moldes atuais, seja possível atentar para 
as possíveis brechas que se apresentarem nesse espaço. Isso seria um modo de resistência e uma prática educativa permeada pela prática da liberdade.

Para Foucault (2012), a relação de si consigo mesmo, também chamada de governabilidade é uma das principais formas de resistência aos poderes instituídos que entram em conflito com a liberdade do sujeito. Na sua concepção, essa governabilidade implica no "conjunto das práticas pelas quais é possível constituir, definir, organizar, instrumentalizar as estratégias que os indivíduos em sua liberdade podem ter uns em relação aos outros" (FOUCAULT, 2012, p. 279).

A educação, a partir dessas práticas anteriormente citadas, pode ser concebida como um dos modos pelo qual o sujeito pode cultivar-se a si mesmo. Assim, o processo educativo não seria somente dedicado à transmissão de conhecimentos e tampouco seria pautado exclusivamente por objetivos externos ao sujeito e que são incentivados e valorizados pela normativa moral da sociedade (a conclusão do curso, a inserção no mercado de trabalho etc.), mas passaria a se dedicar ao processo de construção e cultivo do sujeito que, na teoria foucaultiana é o processo de subjetivação.

Para confrontar as atuais formas de assujeitamento com as quais o professor, na condição de pesquisador e produtor de cultura, pode se deparar é necessário buscar na dimensão artística da própria atividade docente, modos de resistência, criando brechas para a subjetivação. Destarte, essa busca por novas formas de subjetivação também configura "uma possível alternativa a experiência formativa", na medida em que invoca "uma atitude ética do pensar, por parte do educador e um compromisso de fazer de sua arte um exercício de (trans)formação de si e do mundo", num momento em que, simultaneamente, devemos nos interrogar sobre a nossa própria formação, além de nos ocuparmos com a formação dos outros, num processo em que a própria vida é concebida como obra de arte (PAGNI, 2012, p. 36-37).

\section{A CONSTITUIÇÃO DE SI A PARTIR DOS MODOS DE SUBJETIVAÇÃO}

A noção de resistência, vista na seção anterior, também contribui para compreender os processos de subjetivação ou modos de existência. Na leitura deleuziana de Foucault, as relações de saber, poder e subjetivação se articulam de modo inesgotável. Enquanto as categorias de saber (educar, punir, curar) são instâncias molares, as categorias de poder (incitar, suscitar, produzir) são instâncias moleculares, sendo que ambos os domínios coexistem e se correlacionam de forma mútua. Já os modos de subjetivação (resistência e reação) correspondem às linhas de fuga. Esse último domínio ou terceira dimensão da força é interpretado por Deleuze como uma equivalência entre as concepções de Espinosa e Foucault. Para Deleuze, a inspiração espinosista na filosofia de Foucault é evidenciada na maneira como a concepção de força é definida como um poder de afetar e ser afetado por outras forças, isto é, por afetos ou encontros (DELEUZE, 2005; MACHADO, 1990).

É a partir dos diferentes encontros vivenciados que podemos exercitar nossa potência a fim de nos diferenciar do que atualmente somos e também dos outros. 
Isso ocorre porque em cada movimento combinatório suscitado nos encontros não é possível antecipar o vir a ser do sujeito. Nesse processo de subjetivação não há possibilidade para qualquer tipo de controle ou planejamento sobre aquilo que emerge a partir do contato com o outro ou mediante as forças do acontecimento. Por isso, a composição de si é um processo vivo e provisório (MANSANO, 2009).

Na leitura deleuziana de Foucault, o sujeito é um composto de forças, um lugar ou uma região do existente cuja paisagem varia em conformidade com o tipo de força que entra em relação com outras forças, como por exemplo, a "força de imaginar, de recordar, de conceber, de querer" (DELEUZE, 2005, p. 132). É esse movimento de choque e entrelaçamento de forças que compõem, sempre provisoriamente, o lado de dentro, de modo que não existe um sujeito, mas uma produção de subjetividade. Essas relações entre as forças são diferenciais e geradoras de singularidades porque sua potência afeta de maneira diversificada, fazendo com que o sujeito exposto a elas, também Ihes atribua um sentido singular. Aqui, o processo de subjetivação é descrito como uma produção de modo de existência, que não pode ser confundido com a noção de sujeito ou a identidade de uma pessoa. $A$ subjetivação é descrita como uma individuação que pode ser particular ou coletiva, e que se caracteriza como "um acontecimento (uma hora do dia, um rio, um vento, uma vida...). É um modo intensivo e não um sujeito pessoal. É uma dimensão específica sem a qual não se poderia ultrapassar o saber nem resistir ao poder" (DELEUZE, 1992, p. 127-128).

Essa produção do sujeito ou subjetivação é considerada uma "operação artista" porque se distancia do domínio das regras codificadas do saber e das regras coercitivas do poder e atua de modo facultativo, na relação com si mesmo, numa "operação que consiste em dobrar a linha do fora", seja para se proteger ou para explorar novas possibilidades de existência (DELEUZE, 1992, p. 145).

Ao considerar as relações de poder como o lado de fora do pensamento e a subjetivação como o lado de dentro, concebemos que assim como as relações de poder somente se afirmam quando se efetuam, similarmente, a relação consigo, que verga tais forças, também só se estabelece na sua efetuação (DELEUZE, 2005).

Essa dobradura da linha equivale ao que Foucault denomina de processo de subjetivação, que é caracterizado como uma experiência a partir da qual a subjetividade é constituída, trata-se de uma "a racionalização de um processo ele mesmo provisório, que redunda em um sujeito, ou melhor, em sujeitos" (FOUCAULT, 2012, p. 256).

A inspiração para a formulação da noção foucaultiana de modos de subjetivação foi encontrada na releitura dos filósofos antigos, estóicos e cínicos, considerados os precursores nessa curvatura da linha que é a arte de si mesmo (DELEUZE, 1992; FOUCAULT, 2013b).

Para Foucault (2013b) essa arte ou cuidado de si ocorria, sobretudo, de uma escolha pessoal. Não se tratava de uma tentativa de normatizar o comportamento de todos, mas de um problema diário de escolha pessoal, de caráter ético-político, no qual o indivíduo decidia se aceitava viver sob determinada forma de governo ou se resistia a ela, modificando a si mesmo. Todavia, poucos optavam 
pela curvatura das forças sobre si mesmo porque isso implicava na adoção de uma série de procedimentos, técnicas de si, cuja prática tinha por objetivo modificar sua conduta em relação a si mesmo e aos outros.

Assim, não se trata meramente de um retorno ao ethos formativo greco-romano e ao seu ideal de modo de vida, mas de um mergulho no nosso próprio ethos que configure uma atualização das preocupações e preceitos filosóficos antigos, expressos a partir das seguintes questões norteadoras: "o que se passa, o que somos e fazemos hoje"? (DELEUZE, 1992, p. 146-147).

Nessa acepção, podemos compreender que a experiência é a utilização que fazemos do saber, para dar sentido à nossa prática. Nos assujeitar a ela ao mesmo tempo em que nela nos subjetivamos, mostra quem somos e o que somos, trata-se de um processo de experimentação de si. O sentido nunca é algo passível de ser descoberto, mas ao contrário, é algo a ser produzido mediante novas maquinações. A experiência na acepção foucaultiana também contempla a multiplicidade do ethos no qual estamos mergulhados, designado como a articulação e a "correlação, em uma cultura, entre campos de saber, tipos de normatividade e formas de subjetividade" (FOUCAULT, 2012, p. 188).

Tanto Foucault quanto Deleuze utilizam a noção de modos de subjetivação para designar a experiência, não no sentido individual ou coletivo, mas como algo provocado por um jogo de forças que coaduna os elementos interiores e os exteriores, numa intercessão mútua.

Além disso, a atualização da noção de modo de subjetivação também implica na restituição da atitude ética e do compromisso político que, como experiência educativa significa um provocativo e renovado convite para que as próximas gerações estejam abertas à possibilidade de transformar suas vidas em obras de arte. A transposição dos aportes teóricos de Deleuze e Foucault para o âmbito educacional permite tanto uma leitura dos processos de constituição das subjetividades escolares quanto uma renovada compreensão da docência como uma experiência educativa. (PAGNI, 2012).

A partir da perspectiva de Kohan (2000), podemos questionar: Quem somos? Como somos? E o que podemos (e queremos) vir a ser? Respectivamente, tais questões remetem à busca pelos procedimentos, regras e técnicas responsáveis pela constituição de nossa subjetividade; ao reconhecimento e compreensão dos pressupostos e consequências de tais dispositivos; e, finalmente, a resistência aos dispositivos de subjetivação dominantes.

Mediante a perspectiva de Pagni (2012), vislumbramos que a intervenção dos dispositivos institucionais na experiência das pessoas pode ser confrontada pela incessante atividade artística de criação de novas possibilidades de vida ou novos modos de existência, seja no interior do próprio espaço institucionalizado onde ocorrem os assujeitamentos dos indivíduos, seja a partir da criação de outros sentidos para a relação consigo mesmo, com outros indivíduos e com ambiente institucionalizado. Em todos esses casos, a diretriz norteadora constante para os professores é uma renovação de sua prática docente como prática de liberdade, na acepção de um comprometimento ético e político com o cuidado de si e dos outros. 
Esse desafio tem sido abordado em muitos estudos recentes em Filosofia da Educação que convergem na utilização dos aportes teóricos deleuzianos e foucaultianos, particularmente das noções de processos de subjetivação e de cuidado de si, como uma alternativa para a tematização da experiência educativa como um fenômeno cultural e como um acontecimento no limiar dos estudos filosóficos e pedagógicos (KOHAN, 2000; 2008; LARROSA, 2002; 2004; PAGNI, 2011; 2012; FREITAS, 2012). Em tais estudos a noção de processo de subjetivação encontra-se coadunada à noção de cuidado de si, extraída do Foucault tardio que, por sua vez, recupera tal noção da prática filosófica socrática e do exercício físico-espiritual (askesis) oriundo da Filosofia cínico-estóica (FOUCAULT, 2010; 2012).

A noção de cuidado de si é trabalhada nos textos foucaultianos como uma alternativa socrático-cínica que estabelece um modo de filosofar que é uma arte de viver em oposição ao filosofar platônico-cartesiano que estabelece o filosofar como busca da verdade e do conhecimento. Nessa última tradição, a arte de viver que concebia a Filosofia como espiritualidade foi inicialmente obscurecida e, posteriormente, abandonada, em prol de uma crescente busca por racionalização e fundamentação epistemológica. Se a Filosofia platônica subordinou a noção de cuidado de si à noção de conhecimento de si, que na Filosofia socrática estavam juntas, com a Filosofia cartesiana moderna, "o cuidado e o conhecimento - a vida e a verdade, a espiritualidade e a Filosofia - separam-se" (KOHAN, 2008, p. 60).

A noção de espiritualidade, tal como é delineada nos textos foucaultianos não tem conotação mística ou religiosa, mas implica na abordagem filosófica de temas como a ascese (askesis), a franqueza (parrhesía) e o cuidado de si (ephiméleia heautoû), tópicos relevantes para se pensar o processo formativo humano na contemporaneidade e que apontam para novas possibilidades de existência (MUCHAIL, 2004; 2011; FREITAS, 2012).

A processo formativo que retoma a estética da existência e se orienta por uma pragmática de si, se estabelece como uma "atitude de vida, frente a si, os outros e o mundo", pois encerra um "conjunto de práticas dialógicas pelas quais alguém deve passar para transformar-se e assim ter acesso à verdade" (KOHAN, 2008, p. 79). A retomada do cuidado de si da Filosofia socrática constituise também como um cuidado com os outros porque a educação filosófica somente é possível no ato de compartilhar o caminho do ensinamento e da aprendizagem com os outros.

Foucault (2004) aponta uma série de exercícios indicados pelos filósofos estóicos que deveriam auxiliar na preparação atlética do sábio. Tais exercícios, denominados de paraskeué, permitiriam ao indivíduo melhores condições para o enfrentamento dos acontecimentos na medida em que eles viessem a ocorrer. Na seção seguinte, discorremos com mais propriedade sobre esses exercícios, também chamados de práticas de si ou técnicas de si. 


\section{PRÁTICAS DE SI}

No pensamento de Foucault, a constituição dos saberes, os mecanismos de dominação e as técnicas de si constituem, respectivamente, campos de reflexão de natureza epistemológica, política e ética (MUCHAIL, 2004). No último Foucault, questões sobre a verdade, o poder e a conduta pessoal se entrelaçam a partir de uma retomada dos modos de vida éticos da cultura greco-romana para "problematizar os atuais modos de existência, em especial aqueles que se instituem como estados de dominação" (PAGNI, 2011, p. 159). Esse nexo entre os planos epistemológico, político, ético e estético desmoronou quando a noção de conhecimento de si sobrepujou a noção de cuidado de si (MUCHAIL, 2011).

Enquanto o sujeito do conhecimento de si tenta responder à fixa questão norteadora principal quem somos nós?, o sujeito do cuidado de si estabelece como prioridade a fluida questão o que podemos nos tornar? Essa última questão está relacionada diretamente ao tópico dos modos de subjetivação, que remete a um sujeito da ação, sempre inacabado, porque está imerso no processo contínuo de se reinventar. Esse sujeito provisório se confronta continuamente com a questão acerca do que ele pode fazer de si mesmo. Esse desafio de transformar o próprio modo de viver implica na prática de exercícios que não constituem uma regra para a vida, mas sim orientações para uma arte de viver. Essa prática ascética é definida como "um exercício de si sobre si mesmo através do qual se procura se elaborar, se transformar e atingir um certo modo de ser" (FOUCAULT, 2012, p. 259).

O conjunto dessas condições para a ascese era chamado de epimeléia heautou ou cuidado de si mesmo. Em linhas gerais, epimeléia heautou designa uma atitude geral, uma forma de atenção e determina ações de caráter purificador e transformador. Como atitude geral, diz respeito a um modo específico de encarar as coisas e de se ocupar consigo, com os outros e com o mundo. Como atenção, implica numa certa maneira interiorizada de olhar, ou seja, trata-se de uma inversão da primazia do exterior (dos outros, do mundo etc.) para estar atento ao que se pensa e ao que se passa conosco. E, finalmente, diz respeito a ações que praticamos em nós mesmos, mediante as quais "nos assumimos, nos modificamos, nos purificamos, nos transformamos e nos transfiguramos" (FOUCAULT, 2004, p. 12).

Foucault (2004) explica que existem três modelos principais no que se refere à questão do cuidado de si: o modelo platônico, o modelo cristão e o modelo helenístico-romano. Na orientação platônica, o cuidado de si é obscurecido pela prioridade conferida ao conhecimento de si. Na orientação cristã, o cuidado de si é substituído pela renúncia de si, caracterizada pelo cuidado com os outros. Somente no modelo historicamente intermediário, baseado na filosofia dos estóicos gregos e romanos, o cuidado de si tem primazia.

Segundo Foucault (2013b, p. 315), "aquele que cuidava de si mesmo tinha que escolher dentre todas as coisas que se podem conhecer através do conhecimento científico apenas aquelas relativas a ele e importantes para a vida". Conforme nossa interpretação, essa atividade seletiva pode ser associada com a noção de bons encontros que Deleuze (2002) estabelece a partir da filosofia de 
Espinosa. Contudo, permanece a questão acerca do que devemos fazer para poder selecionar o que é bom e evitar o que é ruim para a própria vida, com base nos encontros que nos acontecem? A resposta, que nos força a pensar em nossa própria experiência, se reveste de uma importância maior para o nosso estudo, pois está relacionada ao fato de que a noção de cuidado de si possui sempre a necessidade de uma relação com o outro que é o mestre.

Nos termos foucaultianos, é preciso diferenciar entre o trabalho de um professor, que apenas ensina aptidões e capacidades aos seus alunos e o trabalho de um mestre, "que cuida do cuidado que o sujeito tem de si mesmo e que, no amor que tem pelo seu discípulo, encontra a possibilidade de cuidar do cuidado que o discípulo tem de si próprio" (FOUCAULT, 2004, p. 55).

Nessa perspectiva de Foucault há uma nítida oposição entre aquilo que faz um professor e um mestre. Em linhas gerais, enquanto o primeiro estaria ocupado com a tarefa da transmissão de saberes, o último estaria preocupado em garantir "as práticas da espiritualidade (ou as experiências de pensamento)". É importante lembrar que a noção de espiritualidade aqui não tem conotação religiosa, mas se refere à distinção entre os dois caminhos tomados pela Filosofia e que correspondem, respectivamente, às noções de conhecimento de si e cuidado de si. Embora ambas sejam formas de pensamento filosófico, no decorrer da história da Filosofia, as duas vertentes receberam a denominação de "Filosofia" e "espiritualidade" (MUCHAIL, 2011, p. 99).

A "Filosofia" seria uma forma de interrogação acerca do que seria a verdade, o conhecimento e do que seria preciso para que o sujeito tivesse acesso a eles. Já "espiritualidade" diz respeito a um conjunto de exercícios, buscas, técnicas e experiências (como a meditação, a abstinência, a conversão do olhar, a renúncia, a resistência, as modificações de existência etc.) que constituem não o caminho para o conhecimento ao acesso à verdade, mas o preço a ser pago pelo sujeito para que tais objetivos sejam alcançados. Assim, a espiritualidade sustenta que a verdade não é dada ao sujeito por um simples ato de conhecimento, mas demanda um longo processo de preparação para a ascese (askesis) que acarreta a transformação do sujeito, tornando-o capaz de um retorno da verdade sobre si mesmo (FOUCAULT, 2004, p. 15-17).

A transformação do sujeito requer um trabalho sobre si mesmo a partir da parrhesía. De maneira geral, a parrhesía caracteriza uma atitude de franqueza de pensamento, de coração e de palavra. Em outros registros, a parrhesía é referida como uma virtude, um dever e, ainda, uma modalidade de dizer a verdade ou de veridicção, também chamada de a coragem de dizer a verdade (FOUCAULT, 2004; 2010; 2011).

A parrhesía possui dois opositores: um adversário moral que é a lisonja e um adversário técnico que é a retórica. A lisonja é considerada juntamente com a cólera uma forma de abuso em relação ao outro. Enquanto a cólera é o arrebatamento incontrolado e que assume uma forma violenta de exercício de poder, em decorrência da percepção de superioridade que um indivíduo tem em relação ao outro, a lisonja constitui o seu processo inverso e complementar. A cólera constitui a perda do domínio de si e um governo imerecido sobre os outros porque quem não governa a si mesmo não 
pode governar os outros. A lisonja, por sua vez, caracteriza o mesmo problema de uma perspectiva inversa. O indivíduo assume a sua condição de inferioridade em relação ao outro e usa dessa condição para manipular seu superior através de uma linguagem inverídica (que oculta seus verdadeiros pensamentos e sentimentos em relação ao outro) a fim de obter favorecimentos pessoais. Essa atitude agrava o problema porque o discurso mentiroso do lisonjeador apenas reforça o esquema geral do poder abusivo, desviando pequenas doses de poder para proveito pessoal.

Enquanto a lisonja produz no outro uma certa dependência, o discurso franco produz o efeito de preparar o outro para a sua libertação, sua autonomia. Para agradar, o lisonjeador faz uso das regras flexíveis da retórica, que se alteram em conformidade com o objetivo de convencer seu ouvinte. Já no discurso franco, a linguagem não é utilizada em proveito de quem fala, pois o mestre parresiasta não busca benefícios particulares. Na sua atitude marcada pela generosidade, encontramos uma linguagem que também age sobre o outro, mas como parrhesía, ela visa auxiliar o outro a encontrar a sua própria soberania (FOUCAULT, 2004).

Essa atitude também é um compromisso ético e político porque implica em assumir riscos. Ao comprometer sua conduta com a franqueza, o parresiasta pode ser perseguido, agredido, ter sua reputação fraudada, perder sua liberdade e até mesmo a sua vida. Esse risco deve ser assumido de forma consciente porque "é precisamente sobre essa superfície de conflito que se deve definir a parrhesía" (FOUCAULT, 2004, p. 328). Embora a parrhesía não seja uma maneira de ensinar e nem uma pedagogia, ela sempre é dirigida a alguém a quem se quer dizer a verdade ou a quem se quer auxiliar a chegar a sua própria verdade. Não é uma forma de ensino e tampouco há um procedimento pedagógico porque a parrhesía não tem o objetivo de transmitir saberes e não é praticada mediante uma longa preparação na qual o interlocutor possa acompanhar o percurso que vai do conhecido ao desconhecido. Ao contrário, a parrhesía ocorre de forma abrupta, direta e simples, tal como os estóicos romanos pensavam que deveria ser o discurso filosófico (FOUCAULT, 2010).

A parrhesía se posicionava diante de conflitos, ocupando um lugar no embate de forças, nesse "campo agonístico em que se experimentava sem cessar o perigo que há em exercer a palavra verdadeira no campo político" (FOUCAULT, 2010, p. 272). Na parrhesía, não há propriamente um "ensinamento" porque inexiste o caráter transmissivo ou doutrinário, mas implica na vinculação verdadeira entre um mestre e seu discípulo. O estudante confia no mestre porque a relação entre ambos não é pautada pela retórica ou pelo poder abusivo, mas pela erótica, isto é, por um respeito amoroso (FOUCAULT, 2004). O ato educativo do mestre parresiasta está relacionado "à produção de formas de experiências de si que conduzam o indivíduo a tornar-se sujeito de sua própria formação" (FREITAS, 2012, p. 70). Esse é o legado do mestre parresiasta para seus estudantes, a sua pragmática de si, ou seja, o conjunto de práticas de si para consigo que constituem a sua própria vida e que ele apresenta sem adereços aos seus alunos no intuito de que os mesmo atentem e busquem os seus próprios modos de subjetivação.

Embora a parrhesía não possa ser caracterizada como uma maneira de ensinar, para que ela ocorra é imprescindível a figura do mestre parresiasta. As instituições pedagógicas, tal como são 
constituídas e organizadas atualmente, devem ser criticadas. Nos termos foucaultianos, o problema não está no fato de alguém tentar ensinar algo a outro indivíduo, mas nos efeitos de dominação "que farão com que um garoto seja submetido à autoridade arbitrária e inútil de um professor primário; um estudante, à tutela de um professor autoritário etc" (FOUCAULT, 2012, p. 278).

Nesse cenário, trata-se de privilegiar os modos de subjetivação onde o sujeito não quer ser governado de uma determinada forma. Apesar de estar dentro de um sistema onde as relações são permeadas pelo poder, o sujeito deve achar brechas para se constituir a partir de modos inventivos. A partir de uma inflexão sobre si mesmo ele deve construir sua vida buscando "modos de existência cada vez mais livres" (PAGNI, 2012, p. 47). Para tanto, faz-se necessária a presença de um mestre parresiasta que embora detenha mais conhecimento, como visto no texto foucaultiano citado acima, atue em relação ao aluno não a partir de uma relação de sobreposição, mas a partir de um apelo recíproco: ou seja, que tal relação alicerçada no falar/fazer verídico priorize o cuidado de si e não a transmissão de conhecimentos. A esse respeito, Muchail (2011) lembra que Foucault considerava inúteis os saberes meramente eruditos e enciclopédicos que serviam apenas superfluamente como ornamento, mas não tinham utilidade espiritual, na acepção filosófica, como ética de vida.

Nesse sentido, é destacada a tarefa do educador não como uma autoridade moral e transmissora de conhecimentos, mas como uma figura cujo papel principal é cuidar do outro que é o aluno. Especificamente, a experiência do mestre se converte em cuidar do processo de cultivo de si do estudante. Para tanto, é necessário que ele cuide de si mesmo porque isso é um pré-requisito para poder cuidar dos outros. Em outras palavras, se a educação fosse exclusivamente um processo de dominação de sujeitos não haveria nenhuma possibilidade para a prática de liberdade.

Esse cuidado de si é, concomitantemente, o zelo pelo seu próprio processo de cultivo de si e também pelo cultivo de si dos outros. Os educadores se comprometem com o processo de formação desses sujeitos, no qual eles se entendam como sujeitos que integram um grupo, que são históricos, que estão inseridos em determinado processo e que vivem de acordo com determinados valores etc. $O$ padrão ético nessa discussão é evidenciado pelo fato dos sujeitos não poderem perder de vista que cuidar de si mesmo implica em cuidar dos outros: não basta que eu me torne melhor, mas é necessário garantir condições para que o outro também se torne melhor.

Foucault (2012) diferencia a moral da ética, enfatizando que a moral é a condução da vida de acordo com uma prescrição de valores determinados pela sociedade. Isso seria viver moralmente. A ética, por sua vez, seria a ação refletida do indivíduo sobre si mesmo. A ética tem essa dimensão de individualidade. Agir eticamente é cuidar de si e agir conforme suas próprias reflexões a partir dos padrões estabelecidos. $O$ trabalho de um professor que queira adotar essa perspectiva do cuidado de si deve tentar exercitar uma contra-afirmação em nosso contexto histórico que contribui para competitividade, tornando as pessoas individualistas e egoístas. Em outras palavras, construir a sua vida como obra de arte é construir uma vida não individualista: é dizer eu estou preocupado comigo, mas também estou preocupado com o outro. 
A esse respeito podemos observar que abordar a problemática da subjetividade a partir da noção de modos de subjetivação articulada com a noção de cuidado de si não serve especificamente como crítica ao conhecimento e nem como crítica ao ensino atual. Todavia, a consciência acerca da tensão existente entre a priorização do conhecimento e a priorização do cultivo de si é uma forma importante para "problematizar o lugar comum onde nos colocamos como professor e onde colocamos o aluno" (GELAMO, 2009, p. 113). Dessa maneira, o cuidado de si é pensado como uma forma de resistência a determinadas formas de dogmatização e de governo que se encontram no espaço da ação docente e que podem ser exemplificados mediante a excessiva preocupação por parte dos professores em relação à aquisição de conhecimento por parte dos alunos, bem como à reprodução de conteúdos e a repetição de argumentos teóricos previamente estabelecidos. A imagem das alturas prepondera com suas determinações e rigidez, nos convertendo, às maneiras de ser já estabelecidas.

Nessa situação a dimensão do cuidado de si fica, na melhor das hipóteses, marginalizado. A alternativa então, implicaria em um mergulho em si mesmo, ou um mergulho na vida para um equilíbrio dessa espiritualidade perdida e sobrepujada pelo conhecimento de si, em "interrogarmo-nos sobre o que somos nós como professores e sobre o modo como o si mesmo que nos constitui se plasma no ensino". (GELAMO, 2009, p. 116).

\section{CONSIDERAÇÕES FINAIS}

As relações de poder são exercidas nos mais diferentes espaços sociais. Na perspectiva foucaultiana, é preciso evidenciar, dentro deste processo de sujeição e resistência um não querer ser governado de qualquer maneira. Em outras palavras, é necessário encontrar na instituição educacional e no processo formativo elementos que permitam ao sujeito construir a si mesmo de uma forma bela.

Trata-se de uma proposta para pensarmos alternativamente no processo formativo como uma forma do sujeito agir sobre si mesmo a partir de suas próprias experiências e tentar construir-se com autonomia. Nesse tipo de existência, a ética e a política estão entrelaçadas porque se um sujeito almeja uma boa reputação além de poder governar os outros, ele teria que decidir conscientemente por esse tipo de vida. Isso implica em aceitar determinadas obrigações, bem como transformar seus valores, costumes e condutas a partir de procedimentos ou técnicas específicas no intuito de se preparar tanto para o transcorrer habitual da vida quanto para as adversidades.

Nesse sentido, é destacada a tarefa do educador não como uma autoridade moral e transmissora de conhecimentos, mas como uma figura cujo papel principal é cuidar do outro que é o aluno. Especificamente, a experiência do mestre se converte em cuidar do processo de cultivo de si do estudante. Para tanto, é necessário que ele cuide de si mesmo porque isso é um pré-requisito para poder cuidar dos outros. Em outras palavras, se a educação fosse exclusivamente um processo de dominação de sujeitos não haveria nenhuma possibilidade para a prática de liberdade. Todavia, se a educação é também um processo de cuidar de si mesmo, então, esse cultivo de si é o fundamento da liberdade porque o sujeito só pode ser livre e autônomo se cuidar de si mesmo. 
Nessa perspectiva, as instituições educacionais não devem ser consideradas exclusivamente como o espaço para o conhecimento, mas também como o espaço do cuidado de si. Tradicionalmente, o espaço educacional tem sido pensado a partir do foco da transmissão do conhecimento. Todavia, pelo viés do cuidado de si, o processo educativo e a instituição escolar ganham outro foco que passa a ser a construção da sua vida como obra de arte. Desse modo, seria possível encontrar na escola elementos que permitam ao sujeito e para aqueles que os rodeia construir a si mesmo como uma obra de arte.

\section{REFERÊNCIAS}

1. ASPIS, Renata Lima. Um ensino de Filosofia e resistência política e (des)governamentalidade e subversões. Educação em Revista, v. 12, n.1, p. 169-180, Jan./Jun. 2011.

2. DELEUZE, Gilles. Conversações. Trad. Peter Pál Pelbart. São Paulo: Editora 34, 1992. Foucault. Trad. Claudia Sant'Anna Martins. São Paulo: Brasiliense, 2005.

4. FOUCAULT, Michel. A hermenêutica do sujeito. Trad. Márcio Alves da Fonseca e Salma Tannus Muchail. São Paulo: Martins Fontes, 2004. O governo de si e dos outros. Trad. Eduardo Brandão. São Paulo: Martins Fontes, 2010.

6. Ética, sexualidade e política. Trad. Elisa Monteiro e Inês Altran Dourado Barbosa. Rio de Janeiro: Forense Universitária, 2012.

O sujeito e o poder. In: DREYFUS, Hubert, L.; RABINOW, Paul. Michel Foucault, uma trajetória filosófica: para além do estruturalismo e da hermenêutica. Trad. Vera Portocarrero e Gilda Gomes Carneiro. Rio de Janeiro: Forense Universitária, 2013a. p. 273-295. Michel Foucault entrevistado por Hubert L. Dreyfus e Paul Rabinow. In: DREYFUS, Hubert, L.; RABINOW, Paul. Michel Foucault, uma trajetória filosófica: para além do estruturalismo e da hermenêutica. Trad. Vera Portocarrero e Gilda Gomes Carneiro. Rio de Janeiro: Forense Universitária, 2013b. p. 296-327.

9. FREITAS, Alexandre Simão de. Foucault e a educação: um caso de amor (não) correspondido? In: PAGNI, Pedro Ângelo; BUENO, Sinésio Ferraz; GELAMO, Rodrigo Peloso (Orgs.). Biopolítica, arte de viver e educação. São Paulo: Cultura Acadêmica, 2012. p. 51-73. 
GELAMO, Rodrigo Pelloso. O ensino da filosofia no limiar da contemporaneidade: o que faz o filósofo quando seu ofício é ser professor de filosofia?. Tese (Doutorado em Educação) Universidade Estadual Paulista, Marília-SP, 2009.

11. KOHAN, Walter. Subjetivação, Educação e Filosofia. Perspectiva, Florianópolis, v.18, n.34, 143158, Jul/Dez., 2000. Entre Deleuze e Educação: notas para uma política do pensamento. Educação \& Realidade, Porto Alegre, v.27, n.2, p.123-130, Jul./Dez., 2008.

13. MACHADO, Roberto. Deleuze e Filosofia. Rio de Janeiro: Graal, 1990.

14. MANSANO, Sonia Regina Vargas. Sujeito, subjetividade e modos de subjetivação na contemporaneidade. Revista de Psicologia da Unesp, Assis, v.8, n.2, p. 110-117, Jul./Dez. 2009.

MUCHAIL, Salma Tannus. Foucault, simplesmente. São Paulo: Loyola, 2004. Foucault, mestre do cuidado. São Paulo: Loyola, 2011.

PAGNI, Pedro Ângelo. Entre a modernidade educacional e o modernismo: um ensaio sobre a possibilidade de uma Filosofia da Educação como arte da superfície. In: SEVERINO, A. J.; ALMEIDA, C. R. S.; M. A. LORIERI (Orgs.). Perspectivas da Filosofia da Educação. São Paulo: Cortez Editora, 2011. p. 150-166. Matizes filosófico-educacionais da formação humana e os desafios da arte de viver. In: PAGNI, Pedro Ângelo; BUENO, Sinésio Ferraz; GELAMO, Rodrigo Peloso (Orgs.). Biopolítica, arte de viver e educação. São Paulo: Cultura Acadêmica, 2012. p. 35-50.

\section{Fernanda Antônia Barbosa de Mota}

Doutora em Educação pela Universidade Federal do Piauí (UFPI). Professora Adjunta na área de Filosofia da Educação, vinculada ao Departamento de Fundamentos da Educação na Universidade Federal do Piauí (UFPI). 


\section{Como citar este documento:}

MOTA, Fernanda Antônia Barbosa de. O PROCESSO FORMATIVO DO SUJEITO: GOVERNAMENTALIDADE E MODOS DE SUBJETIVAÇÃO COMO PROCESSO DE SINGULARIZAÇÃO A PARTIR DO CUIDADO DE SI. Reflexão e Ação, Santa Cruz do Sul, v. 26, n. 2, ago. $2018 . \quad$ ISSN 1982-9949. Disponível em: $<$ https://online.unisc.br/seer/index.php/reflex/article/view/11365>. Acesso em:___. Doi :http://dx.doi.org/10.17058/rea.v26i2.11365. 